\title{
Study on the parameters affecting the performance of adsorption cooling system
}

\author{
A.R.El-Ghalban Hamdy Kotb M.S. Obied
}

\author{
Mechanical Power Engineering Department, \\ Faculty of Engineering, Menoufia University, \\ Shebin El-Kom, Egypt.
}

\begin{abstract}
This paper presents numerical simulation of a silica gel/water adsorption refrigeration system. The commercial COMSOL Multiphasics ${ }^{\circledR}$ code is used for simulation which employs the finite element multi-dimensional model for heat and mass transfer processes. The simulation has been carried out for rectangular tube adsorber. The proposed model is validated against available experimental data in the literature. The effects of cycle time, heating temperature, cooling temperature, contact coefficient of heat transfer between grains and heat exchange's surface, evaporator temperature, grain size and adsorbing/desorbing bed layer thickness on the system performance were investigated. The results show that both3-D and 2-D modeling for section of the bed lead to predicting the performance of the entire bed with a good accuracy. One of the main results of this study is that the layer thickness which gives optimal coefficient of performance (COP) doesn't depend on grain size. Moreover the results show that both of COP and specific cooling power (SCP) increase by decreasing grain size.

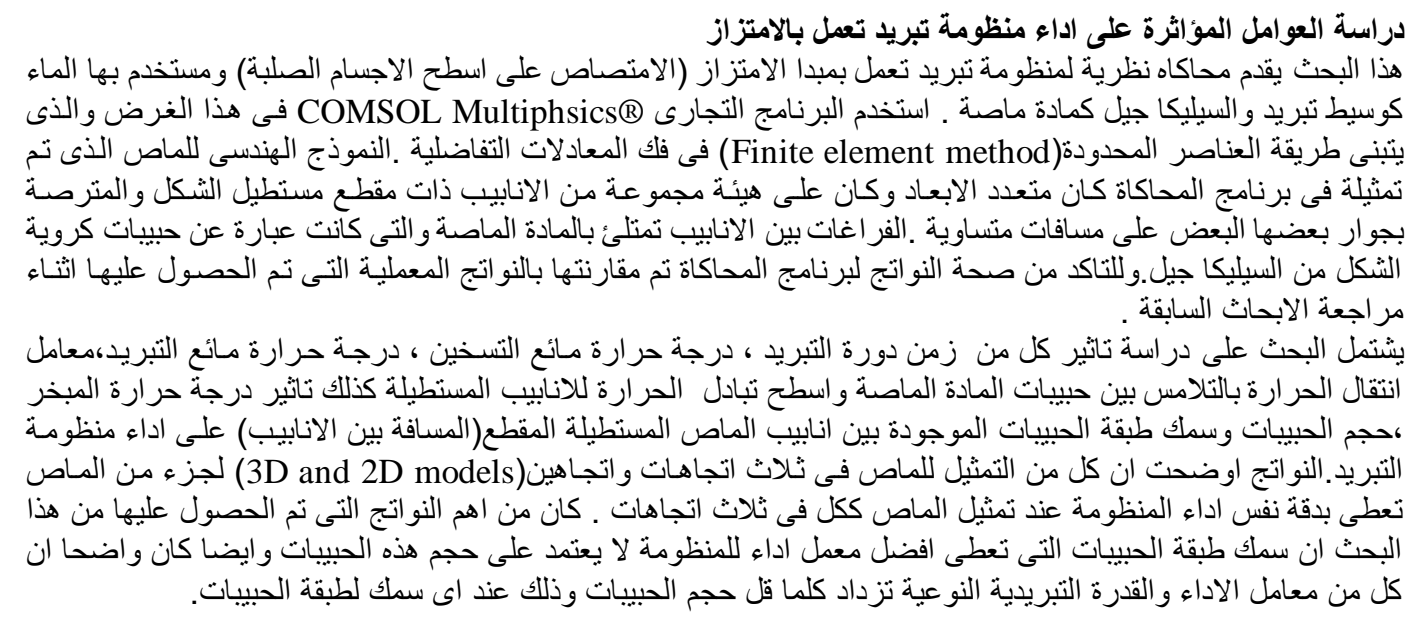

Keywords: Silica gel; Adsorber; COMSOL Multiphysics®; Porous medium; Cooling system

\section{1- INTRODUCTION}

Recently, adsorption cooling systems have been receiving much attention because they can operate with low temperature heat source such as, solar heating systems or exhaust gas heat recovery systems. Moreover their advantages come from being environmental friendly, having noise and vibration free operation and simple working principle [1]. Fig. 1 shows a schematic diagram of a basic two-bed adsorption refrigeration system. Details pertaining to the operation of such a two-bed adsorption chiller could be found in earlier literature [2]. Although the absorption cooling systems are presently the most commonly manufactured form of thermal driven cooling systems, they require relatively hightemperature .A greater risk of crystallization and pumping corrosive liquid are further drawbacks of absorption systems [3]. In case of adsorption cooling systems, these drawbacks don't exist, but adsorption systems have other problems which presented in poor heat and mass transfer mechanisms. So, a lot of researches have been carried out concerning these problems. The adsorbent shape represents an 
important parameter in heat and mass transfer processes. Restuccia et al [4], use pellets in bulk as an adsorbent. Their investigations show that the initial adsorption rate is high due to the large surface of the bulk (relatively high mass transfer). However, the poor thermal conductivity of a bulk and poor contact between pellets and heat exchanger wall causes a steep drop in adsorption rate. This leads to performance characteristics. The use of powder is also unfavourable since the increase in coupled heat and mass transfer rates inside the pulverized adsorbent bed are not encouraging. Most promising technique is the use of thin layer of adsorbent powder mixed with binder brought in contact with heat exchange surface. But unfortunately, the investigations show that it is very difficult to attain a long-time bond between the adsorbent layer and the heat exchange surface. Because of the thermal dilations of the metal and adsorbent are very different during adsorption and desorption processes. Final promising technique is the use of a unilayer of pellets in direct contact with the heat exchange surface which comprises a large mass transfer surface with good heat transport characteristics. The use of unilayer of adsorbent pellets would require a large area of heat exchange surface for the same amount of adsorbent. This indeed increases the thermal capacity ratio between the adsorber heat exchanger and the adsorbent, and this may lead to a poor performance characteristics. Dawoud [5] studied the effect of grain size on water vapour adsorption and desorption into/from one layer of pellets of FAM-Z02.He stated that the small grain size would require large heat exchange area, which agree with the above mentioned statement. Dongsheng Zhu et al [6] studied the case of using a high thermal conductive (HTC) adhesive with exerting pressure on the interface between the adsorbent and metallic surface. They found that both of those deeds reduce the interface contact resistance between the adsorbent and metallic surface significantly, with no noticeable influence on the adsorption capacity of the adsorbent.

Mathematical modeling of the dynamic operation is a primary tool for investigating the effects of system parameters and operating conditions on the performance of adsorption cooling systems. A number of predictive models are available in literature. These models can be classified into the following three main types, lumped parameters (LP) models, heat transfer (HT) models and more sophisticated heat and mass transfer (HMT) models [7]. LP models assume a uniform distribution of temperature, pressure and refrigerant content inside the adsorbent bed [8]. HT models take spatial distribution of the adsorbent temperature into account, but neglect the mass transfer resistance through the porous adsorbent medium [9]. The more complex HMT models account for combined heat and mass transfer during the adsorption/desorption of vapor into/from the adsorbent bed and are able to describe the variation of the adsorbent temperature, adsorbate pressure and uptake with time and space [10]. A lot of researches present numerical investigations of the effect of operating conditions, cycle time, contact resistance, etc. on the performance of finned tubes, bare tubes or flat plate adsorber heat exchangers [10,11,12,13,14,15,16,17], but to the best knowledge of the authors there aren't numerical investigations for rectangular tube adsorber heat exchanger.

This paper presents finite element, multi-dimensional HMT model applied on rectangular tube heat exchanger in water vapor/silica gel adsorber, using COMSOL Multiphysics® code. For Mass transfer two different resistances known as inter-particle and intra-particle resistances are taken into account. The effect of cycle time, heating temperature, cooling temperature, contact coefficient of heat transfer, evaporator temperature, grain size and bed layer thickness on SCP and COP are investigated.

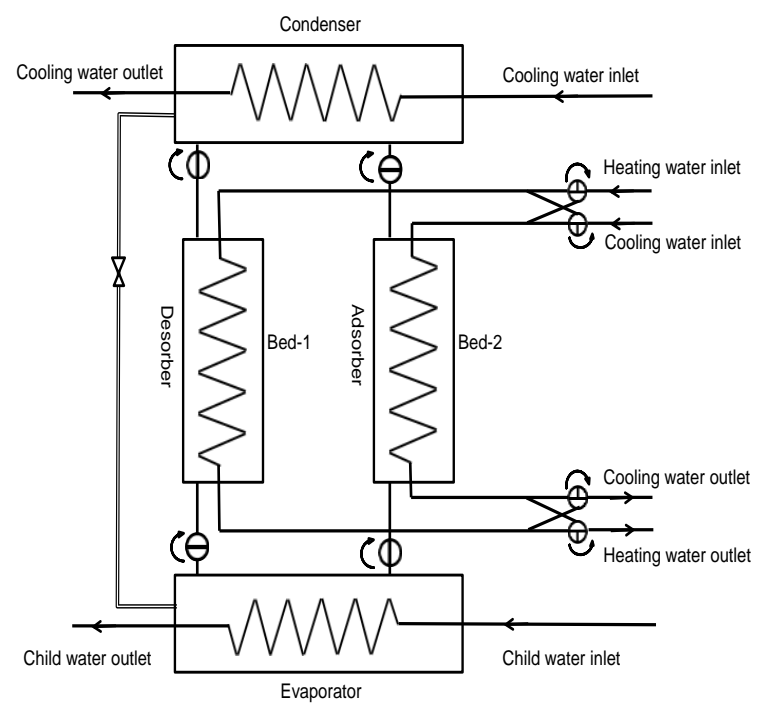

Fig. 1.A syschamatic diagram of adsorption refrigeration system

\section{2- MATHEMATICAL MODELING}

As shown in Fig. 2, the considered adsorber/desorber unit consists of three basic components which are adsorbent material, metal rectangular tubes and cooling/heating fluid. The main simplifying assumptions of the model are as follows:

-Temperatures of condenser and evaporator are assumed constant during condensation and evaporation processes. That means both processes of desorption and adsorption are assumed isobaric.

- The particles in the adsorbent bed are spherical with a uniform size and porosity. 
- Heat losses through the chamber walls are neglected

- The physical properties of tube and adsorbent materials' are constant.

- Under operating conditions water vapor assumed as an ideal gas.

Values for the physical properties and constant parameters used in the mathematical model are listed in the following table;

Table 1: Simulation parameters

\begin{tabular}{|c|c|}
\hline Parameter & Value \\
\hline$D_{\text {so }}$ & $2.54 * 10^{-4} \mathrm{~m}^{2} / \mathrm{s}$ \\
\hline$E_{a}$ & $2.33 * 10^{6} \mathrm{~J} / \mathrm{kg}$ \\
\hline$\Delta h_{a d s}$ & $2.37 * 10^{6} \mathrm{~J} / \mathrm{kg}$ \\
\hline$C_{m}$ & $900 \mathrm{~J} / \mathrm{kg} . \mathrm{K}$ \\
\hline$C_{p f}$ & $4200 \mathrm{~J} / \mathrm{kg} . \mathrm{K}$ \\
\hline$C_{a b}$ & 921J/kg.K \\
\hline$C_{p v}$ & 1874 J/kg.K \\
\hline$\rho_{m}$ & $2700 \mathrm{~kg} / \mathrm{m}^{3}$ \\
\hline$h_{\text {conv }}$ & $300 \mathrm{~W} / \mathrm{m}^{2} \cdot \mathrm{K}$ \\
\hline$\rho_{f}$ & $1000 \mathrm{~kg} / \mathrm{m}^{3}$ \\
\hline$\rho_{a b}$ & $2129 \mathrm{~kg} / \mathrm{m}^{3}$ \\
\hline$k_{m}$ & $160 \mathrm{w} / \mathrm{m} . \mathrm{K}$ \\
\hline$k_{v}$ & $0.198 \mathrm{w} / \mathrm{m} . \mathrm{K}$ \\
\hline$k_{a b}$ & $0.198 \mathrm{w} / \mathrm{m} . \mathrm{K}$ \\
\hline$\epsilon_{b}$ & 0.36 \\
\hline$\epsilon_{p}$ & 0.46 \\
\hline$\mu_{v}$ & $1.08 * 10^{-5}$ Pa.s \\
\hline $\mathrm{R}$ & $461.88 \mathrm{~J} / \mathrm{kg} . \mathrm{K}$ \\
\hline
\end{tabular}

\subsection{GOVERNING EQUATIONS}

Using the prementioned assumptions, the equations governing operation of adsorption system are obtained basing on mass and energy conservation principles applied on the system components (cooling/heating fluid, metal tube and adsorbent bed) as follows:

\section{-Energy balance for thermal fluid:-}

$\rho_{f} C_{p f} \frac{d T_{f}}{d t}+\nabla\left(-k_{f} \nabla T_{f}\right)=-\rho_{f} C_{p f} \overrightarrow{u_{f}} \nabla T_{f}$

- Energy balance for metal:- $\rho_{m} C_{m} \frac{d T_{m}}{d t}+\nabla\left(-k_{m} \nabla T_{m}\right)=0$

- Energy balance for adsorbent bed:-

$$
\begin{aligned}
& {\left[\left(1-\varepsilon_{t}\right) \rho_{a b}(1+w) C_{a b, e q}+\varepsilon_{t} \rho_{v} C_{p v}\right] \frac{\partial T_{a b}}{\partial t}} \\
& +\nabla\left(-k_{a b} \nabla T_{s}\right)+\nabla\left(\rho_{v} C_{p v} \overrightarrow{u_{v}} T_{s}\right) \\
& =\left(1-\varepsilon_{t}\right) \rho_{a b} \Delta h_{a d s} \frac{\partial w}{\partial t}
\end{aligned}
$$

Where;

$\varepsilon_{t}=\varepsilon_{b}+\left(1-\varepsilon_{b}\right) \varepsilon_{p}$

$\rho_{v}=\frac{p}{R T_{a b}}$

-Mass balance for adsorbent bed:-

$\varepsilon_{t} \frac{\partial \rho_{v}}{\partial t}+\nabla\left(\rho_{v} \overrightarrow{u_{v}}\right)=-\left(1-\varepsilon_{t}\right) \rho_{a b} \frac{\partial w}{\partial t}$

The intra-particle mass transfer resistance is considered using the linear driving force [18].

$\frac{\partial w}{\partial t}=\left(15 D_{s o} \exp \left(\frac{-E_{a}}{R T_{a b}}\right) / r_{p}\right)\left(w^{*}-w\right)$

$\mathrm{w}^{*}$ is the equilibrium uptake at temperature $\mathrm{T}_{\mathrm{s}}$ and pressure p. According to [1], for Silica gel the following correlation has been used.

$$
w^{*}=5.5 * 10^{-12} \exp \left[\frac{\Delta h_{a d s}}{R T}\right] p
$$

The following equation (Darcy's law) gives the velocity of vapor as a viscous flow through porous media:

$\overline{u_{v}}=-\frac{K_{a p p}}{\mu} \nabla p$

Where $K_{a p p}$ is the permeability, which can be calculated from the following equations given by [19].

$$
K_{a p p}=K_{d}+\frac{\varepsilon_{b} \mu}{\tau p} D_{e q}
$$

$K_{d}=\frac{\varepsilon_{b}^{3} d_{p}^{2}}{150\left(1-\varepsilon_{b}\right)^{2}}$ 


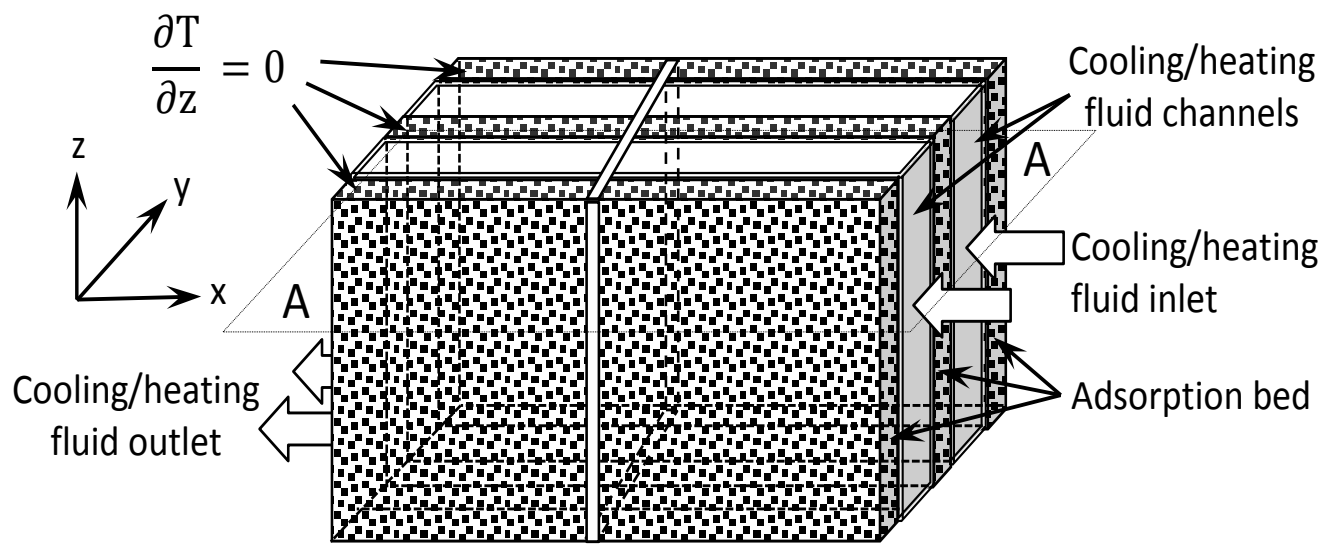

Fig. 2. Schematic layout of adsorption/desorption system

$$
\begin{aligned}
& D_{e q}=\left[1 /\left(0.02628 \sqrt{\left(T_{a b}^{3} / M\right)} / p \sigma^{2} \Omega\right)\right. \\
& +1 /\left(48.5 d_{\text {pore }} \sqrt{\left.T_{a b} / M\right)}\right]^{-1} \\
& d_{\text {pore }}=0.6166 d_{p} \\
& \tau=\varepsilon_{b}^{-0.4}
\end{aligned}
$$

\subsection{CALCULATIONS OF SYSTEM PERFORMANCE}

The rate of heat exchange between heating fluid and desorber bed could be calculated from the following equation:

$$
\begin{gathered}
Q_{i n}=\int_{t_{c 1 / 2}}^{t_{c}} \int_{s} h_{c o n v} A\left(T_{a b}-T_{f}\right) \cdot d s d t \\
Q_{e}=\int_{0}^{t_{c 1 / 2}}\left[L_{v}-C_{p l}\left(T_{c}-T_{e}\right)\right] \dot{m}_{r e f} d t
\end{gathered}
$$

The coefficient of performance can be calculated from:

$$
C O P=\frac{Q_{e}}{Q_{\text {in }}}
$$

Another parameter used to define the operation characteristics of adsorption cooling system is the specific cooling power (SCP) which is the rate of heat added to evaporator per unit mass of adsorbent material. It can be given by the following formula:

$$
S C P=\frac{Q_{e}}{m_{a b} t_{c}}
$$

\subsection{INTIAL AND BOUNDARY CONDITIONS}

The adosrber/desorber bed is assumed at initial temperature and pressure of $\mathrm{T}_{0}, \mathrm{p}_{0}$ respectively. As boundary conditions, there is no heat transfer between outer surfaces of adsorber/desorber components and surrounding vapor. The inlet temperature of the cooling/heating fluid is specified according to the heating or cooling conditions. However, the temperature gradients in the flow direction at its outlet are set to zero. Furthermore, normal pressure gradients to all solid surfaces are set to zero, while the pressure at the adsorbent bed interface is assumed to be equal to the chamber pressure.

$\mathrm{P}_{\text {cham }}=\mathrm{P}_{\mathrm{e}}$ when connected to evaporator.

$\mathrm{P}_{\text {cham }}=\mathrm{P}_{\mathrm{c}}$ when connected to condenser.

$P_{\text {cham }}=P_{\text {cham } 0} \frac{\Delta m+m_{\text {cham } 0}}{m_{\text {cham } 0}} \frac{T_{\text {cham }}}{T_{\text {cham } 0}}$

Where;

$$
\begin{aligned}
& m_{\text {cham } 0}=\frac{P_{\text {cham } 0} V_{\text {cham }}}{R T_{\text {cham } 0}} \\
& \Delta m=\int d t \oiint\left(\rho_{v} u\right) d s
\end{aligned}
$$




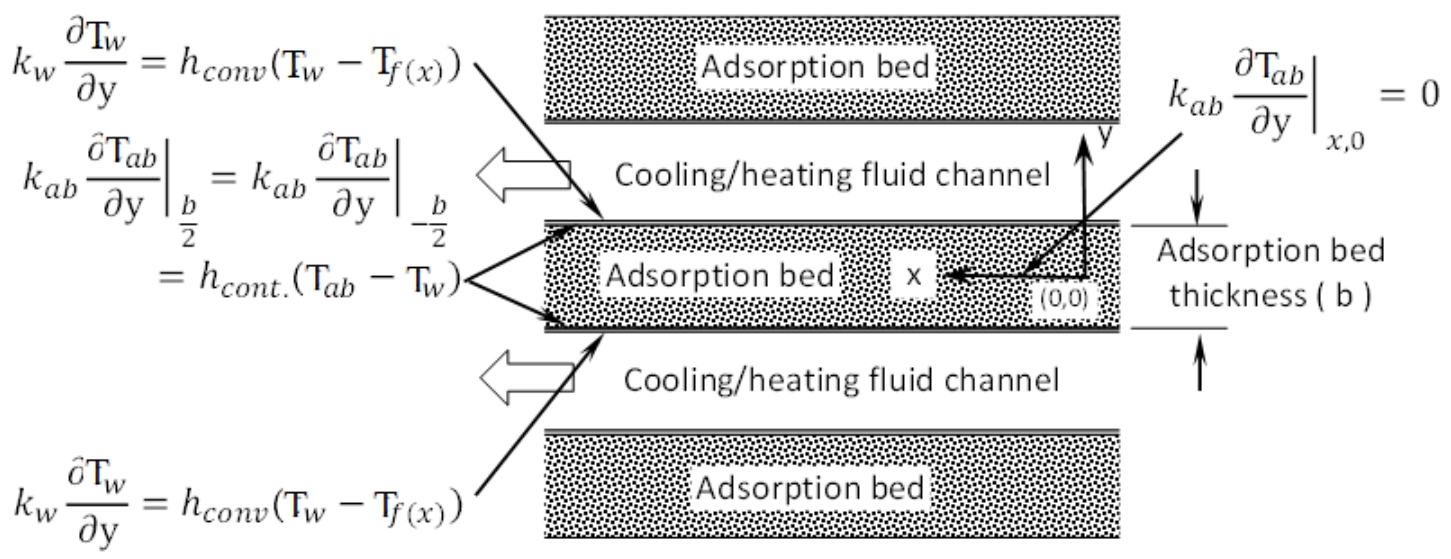

Fig.3. Boundary conditions of adsorbent bed on a section at plane A-A

Where $\mathrm{m}_{\text {cham } 0}$ is the initial mass of the adsorbate in the chamber and $\mathrm{V}_{\text {cham }}$ is the volume of the chamber, $\Delta \mathrm{m}$ is the variation of mass in the chamber after a time step.

Coefficients for heat transfer $h$ and $h_{c}$ for the interface between the adsorbent and metal surface and for the interface between thermal fluid and metal surface assumed to be constant.

\section{MODELING CONSIDERATION}

\subsection{MODEL VALIDATION}

The experimental data given by Freni et al [7] for zeolite FAM-Z02 and water vapor is employed, in order to validate the present numerical scheme. Freni et al carried out the experimental work under the following values for temperature and pressure. For adsorption process, the bed was initially at equilibrium state under uniform temperature of $55^{\circ} \mathrm{C}$ and pressure of 9 mbar. Meanwhile for the desorption process, the equilibrium state was assumed under temperature of $60^{\circ} \mathrm{C}$ and pressure of $50 \mathrm{mbar}$. The inlet temperature of cooling/heating fluid to the adsorbent bed was $35^{\circ} \mathrm{C}$ during the adsorption process and $90^{\circ} \mathrm{C}$ during desorption process. All other specifications of the experimental setup can be found in Freni et al [7]. Fig. 4 gives the time variation of uptake obtained by Freni[7] compared with the corresponding results obtained from the present numerical simulation model. It is clear from the figure that the present simulation model predicts with a good extent the adsorption and desorption processes with a maximum difference of $2.47 \%$ for adsorption process and $11.43 \%$ for desorption process.

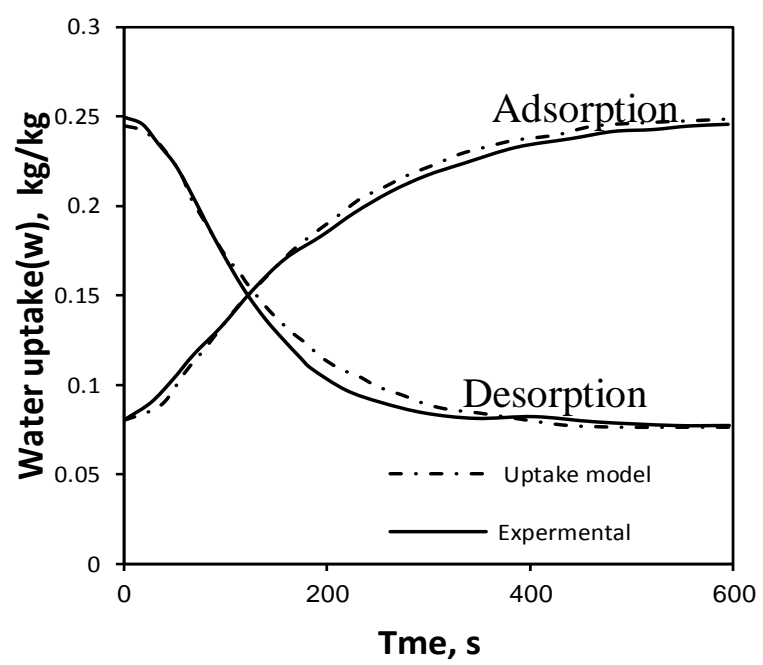

Fig. 4.Comparison between experimental data given by Freni et al [7] and current simulation.

\subsection{MULTIDIMENSIONALITY EFFECT ON THE MODEL ACCURACY}

The discussion in this section aims to declare the effect of multidimensionality on the accuracy of the developed simulation model. Therefore three calculation schemes for heat and mass transfer processes during adsorption and desorption phases have been performed. Firstly a 3-D treatment for the entire bed, secondly 3-D treatment for a section of the bed has been carried out and finally a simpler 2-D calculation for a section of the bed has been performed. The obtained results from the three calculation schemes are presented in Fig. 5 to declare 
the extent of the result dependency on the multidimensionality.

It is clear from this figure that the difference between the results obtained by the three calculation models is very small hence it could be concluded that the $2-\mathrm{D}$ model for a section of the bed can predict with a good accuracy the operating characteristics of adsorption bed. Consequently, from here on out the 2-D model is used to investigate the performance of adsorption cooling system.

\section{4- RESULTS AND DISCUSSION}

The results obtained from the mathematical Simulation model will be presented in this section.

As it is pre mentioned the study aims to declare the influence of the operating and boundary conditions on adsorption bed working characteristics. The presented calculation results show the effect of the different operating parameters and boundary conditions such as cycle time, heating temperature, cooling temperature, contact coefficient of heat transfer between grains and heat exchanger surface, evaporator temperature, grain size and adsorbing/desorbing bed layer thickness on the performance of adsorption refrigeration system.

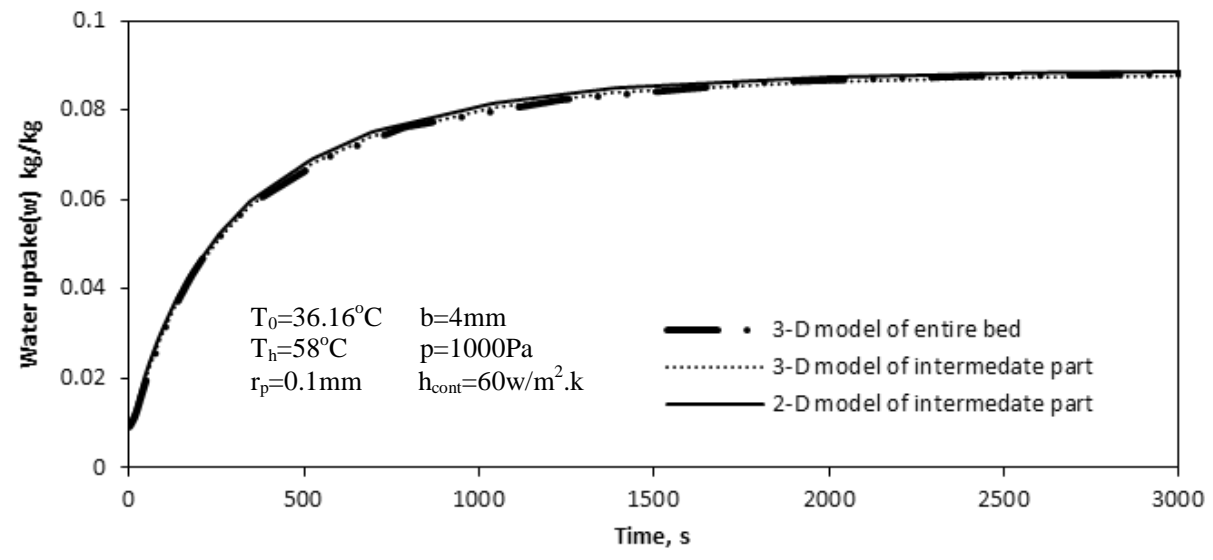

Fig.5 Water uptake versus time obtained by the three simulation models.

\subsection{EFFECT OF CYCLE TIME}

Fig. 6 presents the effects of cycle time on COP and SCP. It is clearly seen that the COP increases monotonically with increasing cycle time. This could reasoned to the increase in the amount of refrigerant that would be extracted during the desorption process and evaporated in the adsorption process which consequently leads to higher cooling effect. This will lead to a favorable effect on the COP. The variation of SCP is not monotonic. It increases from 500 to $900 \mathrm{~s}$, and decreases from 900 to $1400 \mathrm{~s}$. Lower SCP, under a short cycle time, is caused by reduced extent of adsorption, which is also related to a reduced extent of desorption due to short desorber heating period. At a certain cycle time, the maximal adsorption-desorption capacity will be achieved.
Extending the cycle time further will not bring forth any favorable effect on useful cooling, but the SCP will decrease.

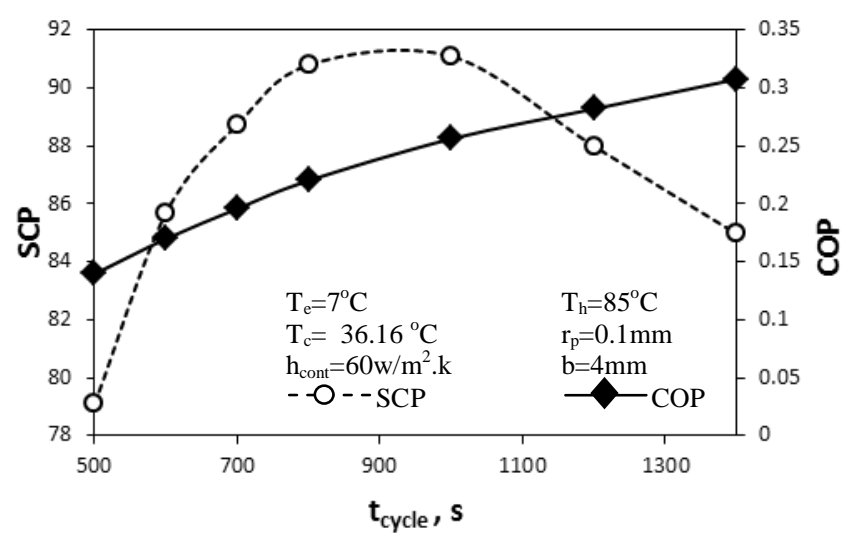

Fig. 6. Influence of cycle time 


\subsection{EFFECT OH HEATING FLUID INLET TEMPERATURE}

The effect of inlet temperature of the heating fluid on both COP and SCP is presented in Fig.7. It is clear that both COP and SCP increase by increasing heating fluid inlet temperature. That is resulted due the increase in the desorbed refrigerant vapor amount by increasing heating temperature and subsequently increasing the cooling effect. But in the same time the increase of heating fluid inlet temperature leads to an increase in heat addition during the desorption process which could be seen in the reduction of the increasing rate of the COP in higher range of heating temperature. Also, it is clearly seen that the SCP increases monotonically with heating temperature that is due to the increase in the desorbed refrigerant vapor amount with the increase of heating temperature as discussed previously.

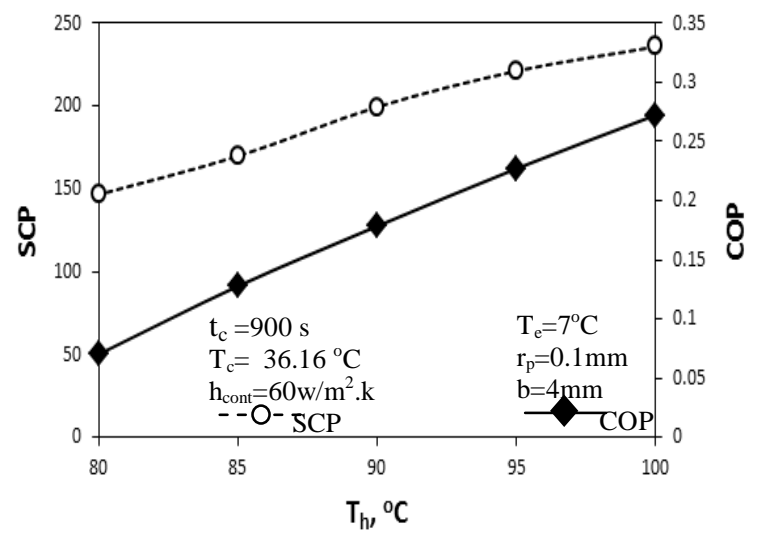

Fig. 7. Influence of heating water inlet temperature

\subsection{EFFECT OF COOLING WATER TEMPERATURE}

The cooling water temperature has a double effect on the adsorption cycle, since the cooling water affects the performance of the adsorber and the condenser of the cycle. The effect of variation of the cooling water temperature is shown in Fig. 8 it is obvious that the increase in cooling water temperature causes decrease in COP and SCP. This could be explained as follows, the increase in cooling water temperature causes reduction in the uptake at the end of adsorption process. And hence reduction in cycle amount of refrigerant. This means lower cycle cooling effect which in turn causes a decrease in both COP and SCP. In the other hand the increase in cooling water temperature leads to an increase in condensation pressure $(\mathrm{Pc})$. Which results in an increases in the uptake at the end of desorption process which leads also in reduction in cycle net amount of refrigerant and hence less COP and SCP.

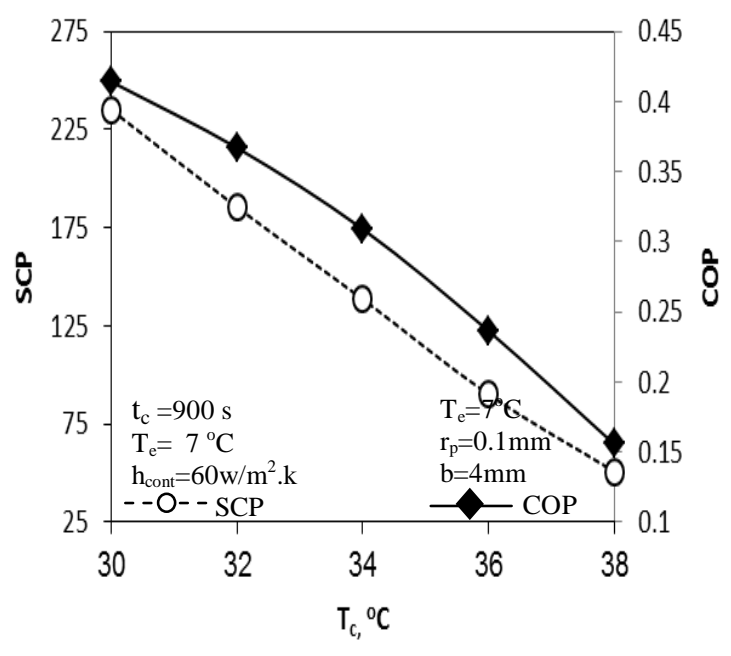

Fig. 8. Influence of cooling water inlet temperature

\subsection{EFFECTS OF EVAPORATOR TEMPERATURE}

The evaporator temperature with accordance to the evaporator pressure $\left(\mathrm{P}_{\mathrm{e}}\right)$ designates the maximum achievable adsorption amount together with the cooling water temperature of the adsorber. As mentioned previously an increase of the adsorbed amount implies a positive effect on both COP and SCP. Therefor increasing the evaporator temperature and consequently the evaporator pressure increases the achievable uptake at the end of the adsorption process as show in Fig. 9, so that increasing evaporator temperature will increase both COP and SCP as show in Fig. 10.

\subsection{CONTACT COEFFECIENT BETWEEN GRAINS AND HEAT EXHANGE SURFACE}

The contact heat transfer coefficient between adsorption bed grains and heat exchange surface affects significantly the performance of adsorption systems because it controls heat transfer process in adsorption and desorption processes and consequently determine the cycle net amount of extracted refrigerant. This coefficient depends on gas nature, temperature and pressure. Aristov [20] concluded also that this coefficient is not a welldefined experimental parameter because its value measured under quasi-equilibrium conditions may differ from that at real conditions of adsorption cooling cycle. Therefore this study reviles the effect of the contact heat transfer coefficient on system performance over the range from 40 to $120 \mathrm{w} / \mathrm{m}^{2} \mathrm{~K}$. The effect of this coefficient on both COP and SCP could be seen in Fig. 11. It is clear that the increase heat transfer contact coefficient increases COP and SCP. 


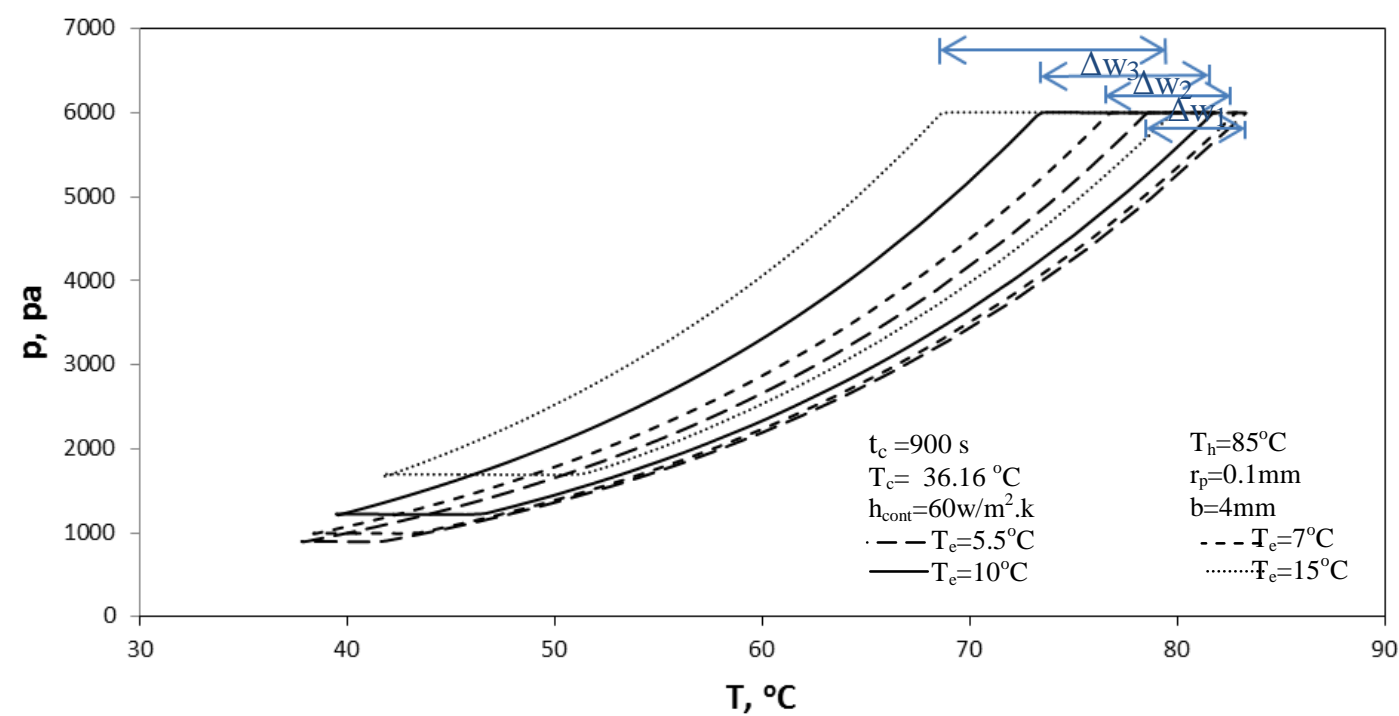

Fig. 9. Influence of evaporator temperature (evaporator pressure) on Capeyron diagram

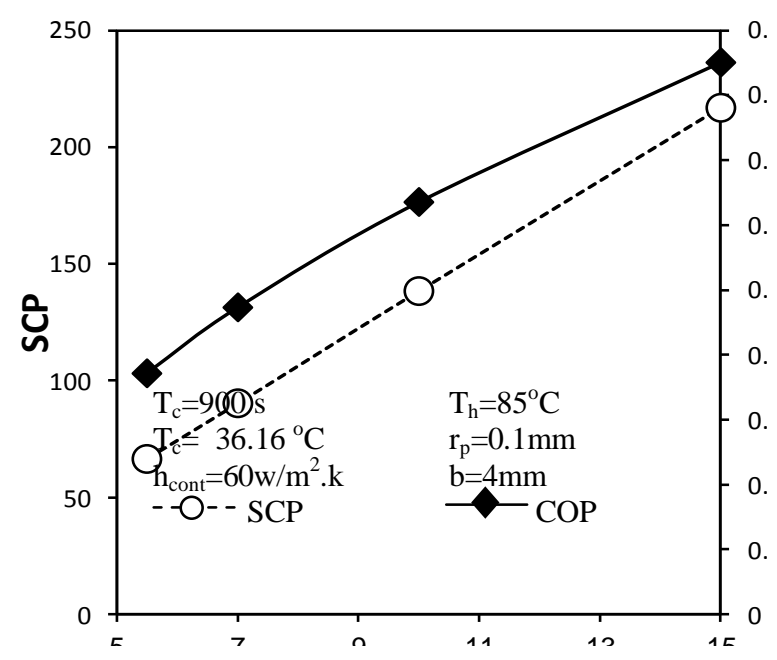

\subsection{EFFECT OF GRAIN SIZE}

Fig.12 shows the effect of grain size on COP and SCP respectively. In fact the larger the grain size, the longer the path that vapor particle has to travel to reach the grain core and hence the higher interparticle mass transfer resistance. It is also a fact that the total surface area for mass transfer increases for the same mass of adsorbent by using smaller grain size. That means the smaller grain size the higher the achievable uptake which results in higher cooling effect and hence an increase in SCP and COP as it could be seen in Fig. 12.

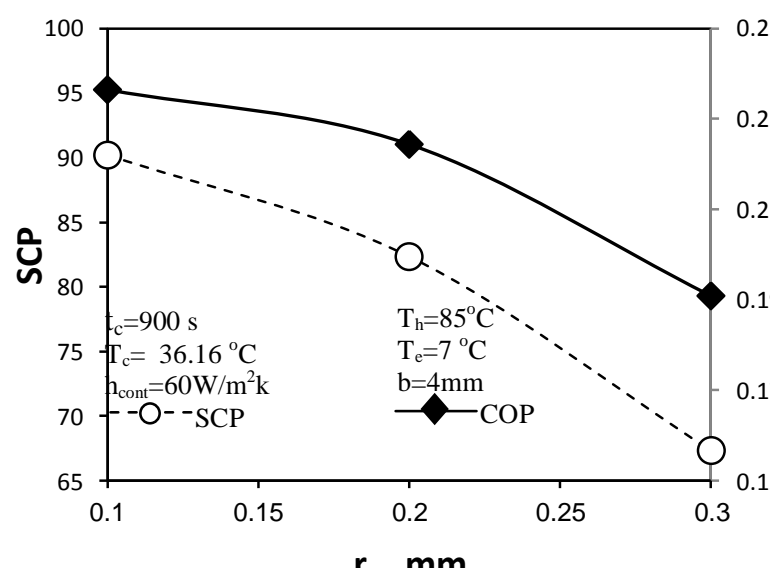

Fig.12. Influence of pellets size

\subsection{THE EFFECT OF BED LAYER THICKNESS}

Fig.13 presents the effects of grains layer thickness on SCP and COP. It is clearly seen that the SCP decreases monotonically with grains layer thickness. 
The reason can be explained as follows: With a thick grains layer, the specific heat rejected during adsorption and specific heat added during desorption are reduced contrary to that of a thin grains layer that is due to increase thermal resistance of grains layer with increase its thickness. The low specific heats tend to low adsorption and desorption amount, this will lead to a remarkable reduction on the SCP. The variation of COP is not monotonic. It increases from 1 to $3 \mathrm{~mm}$, and decreases from 3 to $6 \mathrm{~mm}$. Lower COP, under a thin grains layer, is caused by increased the thermal capacity ratio between the adsorber heat exchanger and the adsorbent. The metal works as thermal storage but finally, its energy is wasted to coolant fluid. In case of thick layer, the low COP is due to the low adsorbed and desorbed amounts during adsorption and desorption phases, respectively. The figure illustrated three grains size. One can note that, in three cases the optimal thickness of grain layer is about $3 \mathrm{~mm}$ that is due to the grains layer mass is constant in all grains sizes because constant bed porosity is assumed in all sizes so the thermal capacity ratio between the adsorber heat exchanger and the adsorbent not varies with grains size .Consequently, the optimal layer thickness not varies with grains size.

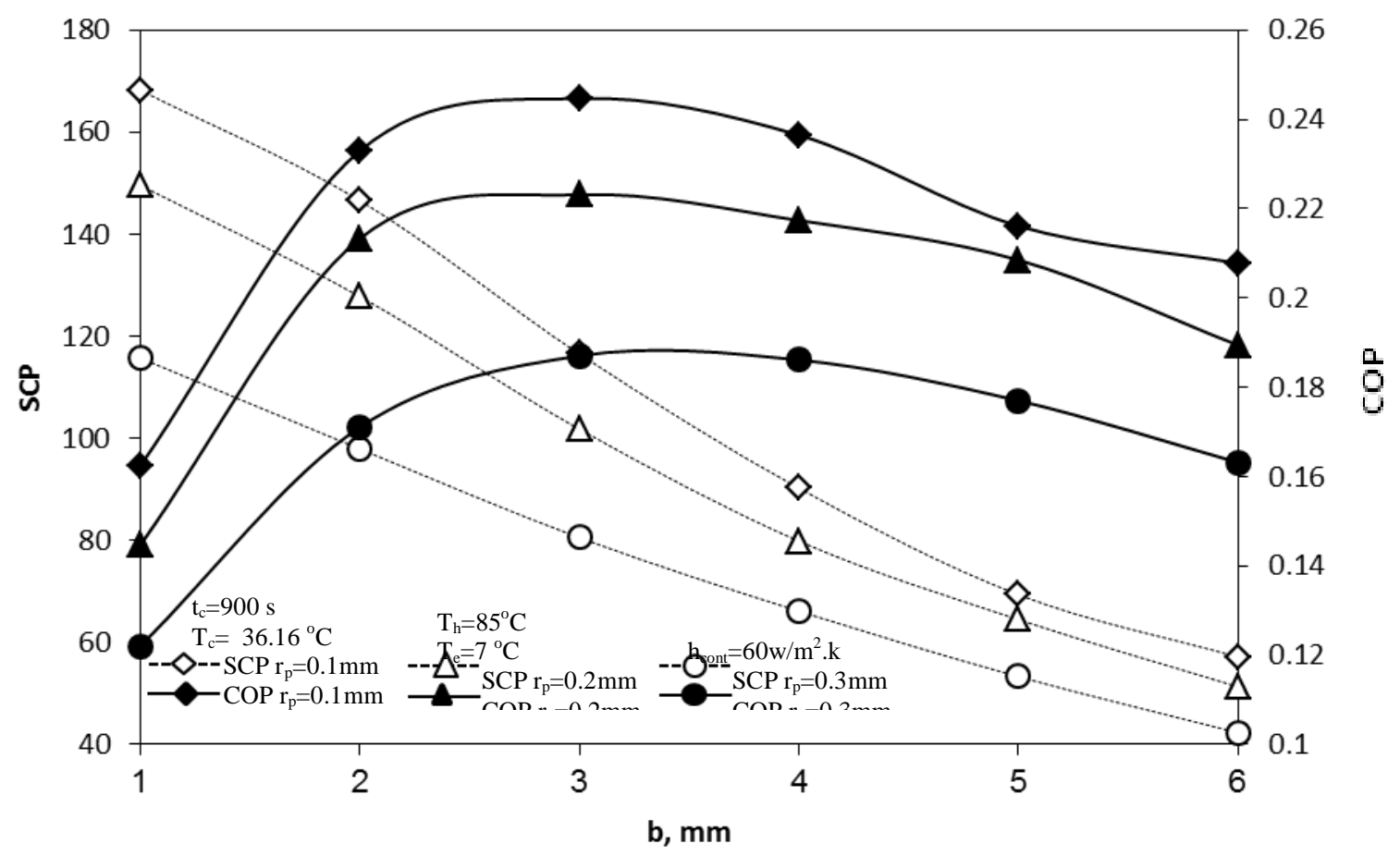

Fig.13 . Influence of grains layer thickness at various adsorbent particle size

\section{5- CONCLUSIONS}

A multi-dimensional non-equilibrium model which takes into account both the adsorption kinetics inside the adsorbent grains and the external mass transfer resistance has been proposed based on the heat and mass balances on control volumes in the adsorber .Through finite element simulation using COMSOL Multiphasics $®$. The simulation shows that:

1- The 3-D and 2-D models of intermediate part of the bed have the same results of 3-D model of entire bed.

2- It was found that the system performance can be strongly influenced by the cycle time, heating temperature, cooling water temperature, evaporator temperature grains size and the grains layer thickness.

3- The optimal thickness of the grains layer is about $3 \mathrm{~mm}$ regardless of grains size

\section{NOMENCLATURE}

$\begin{array}{ll}\text { A } & \text { Area, } \mathrm{m}^{2} \\ \mathrm{~b} & \text { The grains layer thickness, mm } \\ \mathrm{C}_{\mathrm{p}} & \begin{array}{l}\text { Specific heat capacity at constant } \\ \text { pressure, } \mathrm{J} \mathrm{kg}^{-1} \mathrm{~K}^{-1}\end{array} \\ \mathrm{C}_{\mathrm{ab}} & \begin{array}{l}\text { Specific heat capacity of } \\ \text { adsorbent bed, } \mathrm{J} \mathrm{kg}^{-1} \mathrm{~K}^{-1}\end{array} \\ \mathrm{C}_{\mathrm{m}} & \begin{array}{l}\text { Specific heat capacity of metal, } \mathrm{J} \\ \mathrm{kg}^{-1} \mathrm{~K}^{-1}\end{array} \\ \mathrm{COP} & \text { Coefficient of performance }\end{array}$




\begin{tabular}{|c|c|}
\hline $\mathrm{D}_{\mathrm{so}}$ & $\begin{array}{l}\text { Pre-exponent constant of surface } \\
\text { diffusivity, } \mathrm{m}^{2} \mathrm{~s}^{-1}\end{array}$ \\
\hline $\mathrm{D}_{\mathrm{eq}}$ & $\begin{array}{l}\text { Equivalent Kundsen diffusivity, } \\
\mathrm{m}^{2} \mathrm{~s}^{-1}\end{array}$ \\
\hline$d_{p}$ & Adsorbent particle diameter, $\mathrm{m}$ \\
\hline$d_{\text {pore }}$ & Equivalent pore diameter, $\mathrm{m}$ \\
\hline $\mathrm{E}_{\mathrm{a}}$ & $\begin{array}{l}\text { Activation energy of surface } \\
\text { diffusion, } \mathrm{J} \mathrm{mol}^{-1}\end{array}$ \\
\hline $\mathrm{h}_{\text {conv }}$ & $\begin{array}{l}\text { Convective heat transfer } \\
\text { coefficient, } \mathrm{W} \mathrm{m}^{-2} \mathrm{~K}^{-1}\end{array}$ \\
\hline $\mathrm{h}_{\text {cont }}$ & $\begin{array}{l}\text { Contact heat transfer coefficient, } \\
\mathrm{W} \mathrm{m} \mathrm{m}^{-2} \mathrm{~K}^{-1}\end{array}$ \\
\hline
\end{tabular}

$\mathrm{k}$

$\mathrm{K}_{\mathrm{app}}$

$\mathrm{K}_{\mathrm{d}}$

$\mathrm{L}_{\mathrm{v}}$

$\mathrm{M}$

$\tilde{m}$

$m$

$\mathrm{P}$

$\mathrm{Q}$

$\mathrm{R}$

$r_{p}$

$\mathrm{S}$

SCP

$\mathrm{T}$

$\mathrm{t}$

$t_{c}$

$\mathrm{t}_{\mathrm{c} 1 / 2}$

$\vec{u}$

$\mathrm{W}$

$\mathrm{w}^{*}$

V

\section{Greek Symbols}

$\begin{array}{ll}\Delta h_{a d s} & \begin{array}{l}\text { Equilibrium adsorption heat, } \mathrm{J} \mathrm{kg}^{-1} \\ \Delta \mathrm{m}\end{array} \\ & \text { Change of water vapor mass in the } \\ \varepsilon & \text { Chamber, } \mathrm{kg} \\ \rho & \text { Porosity,- } \\ \sigma & \text { Density, } \mathrm{kg} \mathrm{m}^{-3} \\ \tau & \text { Collision diameter for Lennard-Jones } \\ \mu & \text { potential, A } \\ \Omega & \text { Tortuosity factor, - } \\ \Omega & \text { Dynamic viscosity of refrigerant gas, } \\ & \text { Pa .s } \\ & \text { Collision integral,-- }\end{array}$

$\begin{array}{ll}\text { Subscripts } & \\ 0 & \text { Intial } \\ \mathrm{ab} & \text { Adsorbent bed } \\ \mathrm{b} & \text { bed } \\ \mathrm{c} & \text { Cooling, condenser } \\ \mathrm{cham} & \text { Chamber } \\ \mathrm{e} & \text { Evaporator } \\ \mathrm{eq} & \text { Equivalent } \\ \mathrm{f} & \text { Cooling/heating fluid(water) } \\ \mathrm{h} & \text { Heating } \\ \text { in } & \text { Input }\end{array}$

$\begin{array}{ll}1 & \text { Liquid phase of refrigerant(liquid } \\ \mathrm{m} & \text { Water) } \\ \mathrm{p} & \text { Metal } \\ \mathrm{ref} & \text { Particle } \\ \mathrm{t} & \text { Refrigerant(water) } \\ \mathrm{w} & \text { Total } \\ & \text { Wall surface (outer/inner surface of } \\ \mathrm{v} & \text { metal tube) } \\ & \text { Gaseous phase of refrigerant(water } \\ & \text { vapor) }\end{array}$

\section{REFERENCES}

[1] Hamid Niazmand, Iman Dabzadeh, Numerical simulation of heat and mass transfer in adsorbent beds with annular fins, Int. j. Refrig. 35(2012) 581593.

[2] H.T. Chua, K.C. Ng, A. Malek, T. Kashiwagi, A.Akisawa, B.B Saha, Modeling the performance of two bed, silica gel-water adsorption chillers, Int. j. Refrig. 22(1999) 194-204.

[3] S.D. Waszkiewicz, M.J. Tierney, H. Saidani Scott, Development of coated, annular fins for adsorption chillers, Appli. Th. Eng Vol.29, 22222227(2009).

[4] Restuccia G, Recupero V, Cacciola G, Rothmeyer M, Zeolite heat pump for demostic heating, Energy 13(1988).

[5] Belal Dawoud, On the effect of grain size on the kinetics of water vapor adsorption and desorption into/from loose pellets of FAM-Z02 under a typical operating condition of adsorption heat pumps, Chemical Engineering of Japan Vol 40.No 13(2007) 1298-1306.

[6] Dongsheng Zhu, Shengwei Wang, Experimental investigation of contact resistance in adsorber of solar adsorption refrigeration, Solar Energy, Vol. 37, No. 3(2002) 177-185.

[7] Angelo Freni, Belal Dawoud, Francesco Cipiti, Stefanie Chmielewski, Gaetoano Maggio, Giovanni Restuccia, Finite element-based simulation of the heat and mass transfer process through an adsorbent bed in an adsorption heat pump/chiller, ASME-ATIUIT 2010 conference, Sorrento, Italy.

[8] B.B Saha, E.C. Boelman, T.Kashiwiagi, Computational analysis of an advanced adsorptionrefrigeration cycle, Energy20(10),(1995),983-994.

[9] L.M. sun, N. Ben Amer, F. Meuunier. Numerical study on coupled heat and mass transfers in adsorber with external fluid heating, Heat Recovery Systems and CHP 15(1),(1995),19-29.

[10] H.T. Chua, K.C. Ng, W. Wang, C.Yap, X.L. Wang, Transient modeling of a two bed silica gelwater adsorption chiller, Int. J. Heat and mass Trans.47(2004),659-669.

[11] A.Hajji, S. Khalloufi, improving the performance of adsorption heat exchangers using a 
finned structure,Int. J. Heat Mass Transfer, Vol. 39.No. 8.pp1677-1686(1996).

[12] Li Zhi Zhang, Ling Wang, Performance estimation of an adsorption cooling system for automobile waste heat recovery, Appli. Th. Eng.Vol.17 No12,1127-1139(1997).

[13] Li Zhi Zhang, Ling Wang, Effect of coupled heat and mass transfers in adsorbent on the performance of a waste heat adsorption cooling unit, Appli. Th. Eng.19,195-215(1999)

[14] L.Marletta, G. Maggio, A.freni, M. Ingrasciottia, G. Restuccia, A non-uniform temperature nonuniform pressure dynamic model of heat and mass transfer in compact adsorbent beds ,Int. J. Heat Mass Transfer, Vol. 45, pp3321-3330(2002).

[15] K.C. Leong, Y. Liu, Numerical modeling of combined heat and mass transfer in the adsorbent bed of a zeolite/water cooling system, ,Appli. Th. Eng.Vol.24 ,2359-2374(2004).
[16] Wei-Dong Wu, Hua Zhang, Da-Wen Sun, Mathematical simulation and experimental study of a modified zeolite $13 \mathrm{X}$-water adsorption refrigeration module, ,Appli. Th. Eng.Vol.29,645- 651(2009).

[17] Douglas B. Riffel, Ursula Wittstadt, Ferdinand P. Schmidt, Tomas Nunez, Francisco A.Belo, Antonio P.F.Leite, Felix Ziegler, Transient modeling of an adsorber using finned-tube heat exchanger, Int. J. Heat Mass Transfer, Vol. 53, pp1473-1482(2010). [18] Akiyoshi Skoda, Motoyuki Suzuki, Fundamental study on solar powered adsorption cooling system, Chem. Eng. Japan,17,39(1984). [19] D.M. Ruthvan, Principles of adsorption and desorption process, j.Wiley\&Sons, NewYork, 196

[20] Yuriy I.Aristov, Optimal adsorbent for adsorptive heat transfers: Dynamic considerations, Int. j. Refrig. 32(2009) 675-686. 